\title{
A SOCIOLINGUISTIC ANALYSIS OF TABOO WORDS IN ALPHA DOG MOVIE
}

\author{
M. Sofyan Al Farisi ${ }^{1}$, Adi $^{2)}$,Endang Setiyo Astuti ${ }^{3)}$ \\ IKIP Budi Utomo Malang \\ msalfarisi29@gmail.com
}

\begin{abstract}
This study is aimed at revealing the types and functions of taboo words uttered by the characters in Alpha dog movie. This study is under the concern of sociolinguistics, which is a branch of linguistics studying language and its functions in society. It also employed a descriptive qualitative method using the researcher and a data sheet as the research instruments. The data of this study were the words, phrases, clauses, and sentences uttered by the characters of Alpha Dog movie and were collected by note taking technique. The data then were analyzed by referential analysis technique. The data triangulations were also employed to confirm the validity of the data. This study reveals the type of taboo words uttered by the characters of Alpha dog movie can be classified into four; Epithet (EP), Profanity (PR), Vulgarity (VU), and Obscenity (OB). The functions of the words were classified into four; to draw attention to oneself (TDA), to show contempt (TSC), to be provocative (TBP) and to mock authority (TMA).
\end{abstract}

Keywords: sociolinguistics, taboo words, Alpha Dog Movie

CPendidikan Bahasa Inggris FPISH IKIP BU Malang

\section{Introduction}

Communication is one of the important parts in human's life. Gamble and Gamble (1984) stated that the relationship can be built with others through communication. Communication is a thing that every living person needs. People are able to share information through communication. People need language as a tool of communication In order to foster a successful communication. Through language, people can put across their feeling or their thinking toward something. They may even show their annoyance, astonishment, hatred, etc. When people are in such condition, they typically use some words, gestures, expression, or other usage generally considered insulting, rude, or vulgar that is in linguistics term called as taboo words.
Taboo terms were firstly introduced by Captain Cook in the late $18^{\text {th }}$ century when he was sent to Tahiti. According to Allan and Burridge (2006). Taboo words are always associated with inappropriate language and it cannot be used in daily conversations. Therefore, taboo words still manage as offensive and savage words in most languages, such as English. Long time ago in America, there were strict rules to avoid the use of taboo words in public such as in printed media. The use of taboo words such as fuck and cunt would lead to prosecution and imprisonment so that they were not used in printed media such as newspaper. However, it seems that nowadays the attitude towards the function of taboo words has already changed. The changes happened because the legal sanctions were disappearing and there were 
tendency that now in some society, people are getting more relaxed to accept taboo words. As a result, taboo words are now commonly found when someone expresses the emotive feeling. The existence of taboo words, the norms of using taboo words may vary among societies, or it can be concluded that nothing is taboo for all people under all circumstances for all time. The list of taboos and their importance may change over time, it also may weaken or even disappear, while others may become stronger and more dominant. Therefore, this study applies Sociolinguistics, as a branch of Linguistic, to identify the taboo words uses in Alpha dog Movie.

The researcher uses a movie entitled Alpha dog as the source of his research. This movie is one of many movies that can be examined through this research in terms of taboo words in Alpha dog movie, the characters frequently use taboo words in their conversations so that the utterances can be analyzed easily. Moreover, Alpha dog movie is a movie that based on a true story which would make the research more easily to be analyzed considering the context would be the same as in real life. Therefore, this movie is worthanalyzing due to the occurrence of taboo words in real life society.

Based on the background above, the purposes of the study are presented below:

1. to identify and describe the types of taboo words uttered by the characters of Alpha dog movie.

2. to describe the functions of taboo words uttered by the characters in alpha dog movie.

Sociolinguistics comes from the word "socio" and "linguistic". Socio has the same meaning with social that is associated with the community. Linguistics is the science that discusses a particular language and language elements and the connection between elements. Sociolinguistics deals with examining the relationships between language and society in order to have better understanding of language structure and the function of language in communication (Wardhaugh, 2006).

One of the two main concerns of sociolinguistics is society. Hornby defines the society as a community of people who are connected to each other for a certain purpose or goal (2000). In communication, people need build social interaction. In sustaining social interaction, people do not speak and write to communicate with themselves, but rather to communicate with others. Another concern in sociolinguistics is language. Language can be simply defined as a means of human interaction. To convey message, people use language. language is also a way of expressing emotive and logical thought. Through language, people can put across their feeling or their thinking toward something. They may even show their annoyance, astonishment, hatred, etc. When people are in such condition, they typically use some words, gestures, expression, or other usage generally considered insulting, rude, or vulgar that is in linguistics term called as taboo words.

A word denoting one of the taboo topics is sometimes called a taboo word/linguistics taboo/verbal taboo. Based on the data analysis all the types of taboo words on taxonomy of Batistella (2005) are: epithets, profanity, vulgarity, and obscenity. And Wardhaugh (2006), 
taboo words are disregarded in particular occasion because they have several functions such as to draw attention to oneself, to show contempt, to be provocative, and to mock authority.

\section{Types of taboo words Epithets}

Epithet is characterized by the existence of several types of slurs, such as bitch and fag. Other references that are included as epithet are connected to race, ethnicity, gender, sexuality, one's appearance, and disabilities such as $n * g g^{*} r, \quad m * d g^{*} t$ and $\quad r * t * r d$, motherf**ker, $t * t$-man (Batistella, 2005). Jay (in Doyle 2006) defines epithet as a short but strong blast of passionate language which is triggered by frustration or anger such as son of $a b^{* *} c h$. Here is an example of epithet in a conversation.

\section{Profanity}

According to Batistella (2005), profanity can be categorized as religious cursing because it usually includes the foul-mouthed use of what is considered to be sacred. Being more detail, Jay in Doyle (2006) describes profanity as the expression involving the use of religious terms in a profane, secular or uncaring manner. The aim of the speaker is not to vilify God or anything connected with religion but it may be used to express emotional response to certain motives. The words that belong to this type are $J *_{s}{ }^{*}{ }_{s} C h r^{*} s t, h * * l, d * * n$, godd ${ }^{* *} n$.

\section{Vulgarity}

Vulgarity and obscenity have the same reference especially to words or expressions that contain sexual anatomy and excretory function in a rough manner. (Batistella, 2005). The difference between vulgarity and obscenity is usually related to the level of prurience. Jay (in Mercury, 1995) asserts that vulgarity is used to humiliate or bring down the thing or individual referred to or described. The words that belong to this type are such as $a^{*} s, t^{*} t, c^{* *} k, d^{* *} k$, and $c^{* *} t$.

\section{Obscenity}

Obscenity refers to expressions that are prohibited from public use since they involve repulsion to the sense, abhorrent, impolite and detestable to morality (Jay, in Doyle, 2009). Moreover, according to Batistella (2005) obscenity is defined as words or expressions which involve sex differentiating anatomy or sexual and excretory function that usually uttered in rough manner. The words that belong to this type are $f^{* * * k}$ and $s * * t$.

\section{Functions of taboo words To draw attention to oneself}

Sometimes people utter taboo words in order to get the attention from the listener. Mc Edward (in Mc Guire 1973) explains that the speakers should gain the interest trough the use of strong, powerful language whose connotation can stimulate an instant reaction from the audience. Therefore, people use taboo words which are believed to have power in gaining listener's attention because of its strong connotation.

\section{To Show Contempt}

The use of taboo words in conversation between two people can also mean to show contempt. 
According to Oxford Advance Learner's Dictionary (1995) contempt means the impression in which a person or may be some thing is totally useless and cannot be regarded. In other words, when someone tries to show contempt by using taboo words, he or she will insult the addressee by uttering words that can offend their pride.

\section{To Be Provocative}

When someone utters taboo words, he or she may have an intention to provoke a certain response such as violation or anger from others. This is in line with Rothwell (in Fitzgerald 2007) who says that verbal obscenity can be the most efficient symbolic process offered to protester intended for inviting chaotic reaction. Taboo words are considered successful when the response is suitable with the speaker's expectation.

\section{To Mock Authority}

Sometimes people use taboo words when they are not satisfied with public images such as government and institutions. Mc Guire, (1973) asserts that verbal obscenity communicates a significant hatred for society's rule, a rebellion against power as well as impertinence for things that are considered sacred. In other words, people used taboo words because they want to express their disappointment about reality that are different from what they have expected. Therefore, some people may prefer to use certain taboo words that are directed to mock authority in order to show their disbelief about governmental stuffs.

\section{Research Method}

This research employed a descriptive qualitative method, since it is involved the collection of data for the purpose of describing the existing condition. Strauss and Corbin (1998) state that qualitative research is achieved not by means of Quantification or statistical technique. It can give complex detail about particular phenomena which are difficult to be expressed with quantitative method. It is acceptable that some of the data may be quantified with the background information of the subjects under the study, yet the more important thing is in its interpretation. According to Vanderstoep and Johnston, the purpose of this type of research tends to be descriptive rather than predictive (2009). In this research, qualitative method is chosen as the appropriate method because it represents what the researcher had studied. This is in line with the aim of this research, to identify the types and describe the function of taboo words.

\section{Results and Discussions}

Almost all characters in the Alpha dog movie seem to have been accustomed to employ taboo words in their daily communication. It can be seen from the frequency of occurrences of taboo words uttered by the characters of the movie in the data sheet. This section is the discussion of the findings in depth. There are two parts of this section. The first part is the discussion related to the types of taboo words in Alpha dog movie and the second part is about the functions of taboo words. The point that is discussed is about the context like when, where and 
why the conversation contains taboo words occur.

\section{Types of taboo words}

In the Alpha dog movie, the four types of taboo words were found, they are epithet, profanity, vulgarity, and obscenity. Each of them is explained one by one below and followed by some examples.

\section{Epithet}

Epithet includes a variety of slurs that are connected to race, ethnicity, gender, sexuality, one's appearance, and disabilities such as $b^{* *} c h, f^{*} g g^{*} t, n^{*} g g^{*} r, b^{*} s r^{*} t^{*} r d$, motherf**ker, and son of a $b^{* *} c h$. Epithet can occur because the one who utters the word is motivated by frustration or anger. Here is the example:

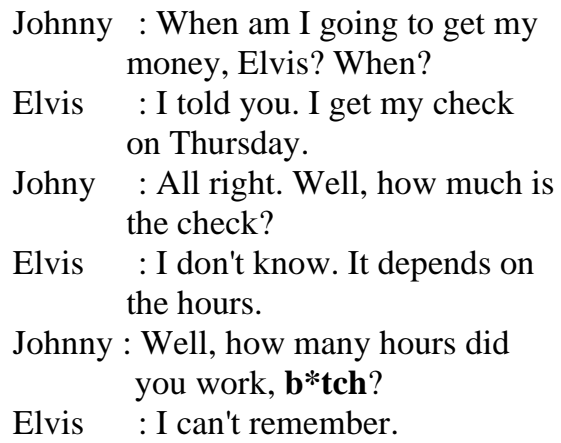

In the dialogue above, Johnny is calling Elvis with $\mathbf{B} *$ tch which is categorized as epithet because it is one of many slurs which refer to sexuality term. B*tch originally means a female dog but it has a different meaning when it is used as a word to insult another person. If the word is directed to a female, it can be meant as a female prostitute who likes to change her sex partner. If it is directed to a male, the word means a homosexual who plays the female role in copulation.

\section{Profanity}

Profanity occurs when someone is using religious terminology in a profane, secular, or uncaring manner such as $J *_{s} *_{s}$ Christ, $h^{* * l,} d^{* *} n$, and Godd**n. Although the terminology is used with those manners, but the intention of the speaker is not actually to denigrate God or anything associated with religion. The term "profane" originates from classical latin "profanus" literally "before (outside) the temple". It carried the meaning of either desecrating what is holy or with secular purpose. Profanity represented secular indifference to religion or religious figures. Here is the example

\section{Zack : Another thing. I'll be sleeping, right? And she'll wake me up by looking at me. Like I'll open my eyes, and she'll be right there looking at me, like... F*cking A! It's god*mn creepy, you know. Like she's in love with me, and breathing on me! \\ Jake : You're lucky, you know that. I mean, my mother, she'd never ...Boo-hoo for me!}

In the dialogue above, there is a taboo word which is categorized in profanity type. The word belongs to profanity because $\mathbf{d}^{*} \mathbf{m n}$ is actually a word that is used in religious contexts such as in church. The word $\mathbf{d}^{*} \mathbf{m n}$ in a church is usually used when the priest explains about condemnation upon someone who is not following Jesus Christ's way of life. Therefore, he or she who is damned by God will suffer eternal punishment in hell. The word becomes taboo because it is used outside the formal circumstance in which profanity is not allowed. In the conversation, Zack utters taboo word d*mn that include in profanity. The word $\mathbf{d}^{*} \mathbf{m n}$ primarily starts with the 
terms "god be dammed" or invocation for god to curse someone or thing. However the aim of Zack uttering the taboo word is not to vilify God or anything connected with religion but it is used to express emotional response about what his mother does.

\section{Vulgarity}

Vulgarity refers to words or expressions that contain sexual anatomy and excretory function in a rough manner such as $a^{*} s, t^{*} t, c^{*} c k$, $d^{*} c k$, and $c^{*} n t$. Vulgarity is believed to demonstrate the raw expression of street language. Therefore the use of vulgar language is usually to humiliate or bring down the thing or individual referred to. Here is the example:

Elvis : Whoa, goddamn it, man! (Johnny holding a gun)

Johnny : All right, motherfucker!

People around : Whoa, whoa, whoa! Come on, man

Jake :You point that thing at me, you better pull the $f^{*}$ cking trigger! Well, come on,you f*cking p*ssy, do it! Come on, $\mathrm{b} *$ tch!

The type of taboo word uttered by Jake in this conversation "p*ssy" is categorized as vulgarity. Jake utters this word to insult Johnny that he is girly for not daring enough to pull the trigger of the gun that he holds and calls with the word p*ssy which actual meaning of this word is a woman's genetial. Meanwhile, in this conversation, Jake utters this taboo word to mock Johnny, to say that he is a weak, cowardly, or effeminate man. This conversation happens in the conflict due to the fail transaction of drugs which is done by Jake that he cannot give Johnny his money and makes him angry.

\section{Obscenity}

Obscenity becomes the most dominant type used by the characters in Alpha dog movie. Obscenity is described as a term which characterized sex differentiating anatomy or sexual and excretory function in a crude way such as $f^{* * k}$ and $s^{* *} t$. Obscenity and vulgarity have the same reference but both are different. The distinction between vulgarity and obscenity is related to the level of prurience. Obscenity is believed to be prohibited from public use since they involve repulsion to the sense, abhorrent, impolite and detestable to morality. Here is the example:

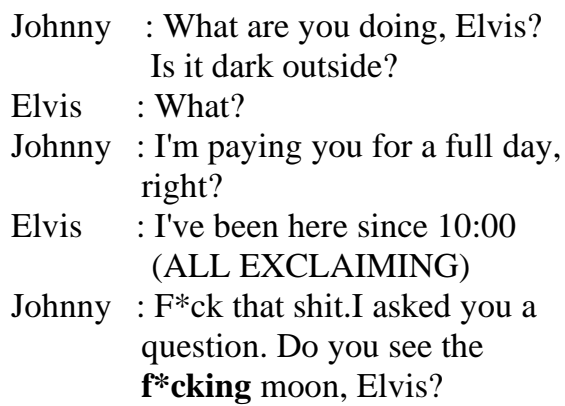

The word f**king usually described a sexual activity in literal meaning. Moreover, that word can trigger disgust to the sense so that it is highly restricted for public use. The other use of this word is for emphasis or to express anger, annoyance, contempt, or surprise. In the example above Johnny utters $\mathbf{f}^{* *}$ king because he is angry to Elvis that can't give his money back.

\section{Functions of taboo words}

All four functions of taboo words, including draw attention to oneself, to be provocative, to show contempt, and to mock authority are all uttered by the characters in Alpha dog movie and some are presented in 
this section with some examples as below:

\section{To draw attention to one self}

This function can occur when someone utters a taboo word which has a strong connotation to gain the listener's attention. Moreover, by using strong and powerful language such as taboo word, the listeners will immediately respond the speaker's utterance.

Here is the example of the function "to draw attention to one self":

$\begin{array}{ll}\text { Elvis } & \text { : It's all done, man. } \\ \text { Johnny } & \text { : Well, I guess you shouldn't have } \\ & \text { finished so fast, huh? (OTHER } \\ & \text { GUYS ARE LAUGHING) } \\ \text { Elvis } & \text { : Shut the f*ck up. } \\ \text { Johnny } & \text { : Never mind that. } \\ & \text { (OTHER GUYS ARE STILL } \\ & \text { LAUGHING) } \\ \text { Elvis } \quad \text { Shut the f*ck up! } & \\ \text { Johnny } & \begin{array}{l}\text { : Never mind that. Get back to } \\ \text { f*cking work. You want shit to } \\ \text { do? Go wash the floors. Scrub out } \\ \text { the toilets. Or better yet, pick up } \\ \text { all the dog shit in the backyard. }\end{array}\end{array}$

In this conversation Elvis utters taboo words in telling guys to stop laughing when he talks to Johnny. $\mathrm{He}$ wants them not to mind other people business. Before this conversation happens, Elvis is outside of the house cleaning stuff that Johnny asks him to do. When he comes into the house, Johnny starting to be annoying by asking him to do more work, so other guys in the room consider Elvis is a slave of Johnny that he would do anything that Johnny ask because he owes Johnny so much money. Knowing that Johnny does that thing to Elvis makes other guys in the room laughing and makes Elvis feel humiliated then tell them to stop laughing and utters taboo word in order to draw the attention.

\section{To show contempt}

This function can occurs when people utter taboo words to show their disrespect feeling toward the addressee. It can be said that the aim of the speaker is to offend their opposite pride because they feel that their opposite partners are completely worthless. To make the definition clearer, here is the example:

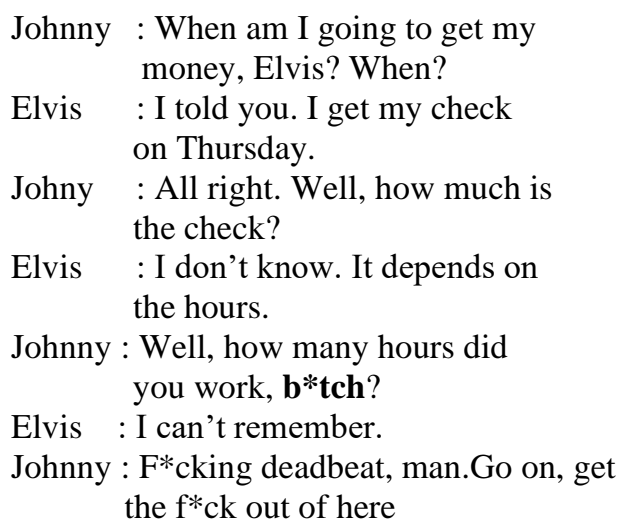

Johny : All right. Well, how much is the check?

Elvis : I don't know. It depends on the hours.

Johnny : Well, how many hours did you work, $\mathbf{b}^{*}$ tch?

Elvis : I can't remember.

Johnny : F*cking deadbeat, man.Go on, get the $\mathrm{f}^{*} \mathrm{ck}$ out of here

The dialogue above takes place in Johnny's house, Elvis is working in Johnny's house cleaning his stuffs because he owes him so much. Due to his debt, Elvis should do anything that Johnny ask him to do and Johnny treats Elvis like he is his slave. This conversation happens when Johnny ask Elvis about when he will get his money back. In the dialogue above, Johnny is calling Elvis with $\mathrm{B} *$ tch. $\mathrm{B} *$ tch originally means a female dog but it has a different meaning when it is used as a word to insult another person. If the word is directed to a female, it can be meant as a female prostitute who likes to change her sex partner. If it is directed to a male, the word means a homosexual who plays the female role in copulation. But 
Johnny calls Elvis with this word is to humiliate him, or to show that Elvis is a worthless man in there.

\section{To be provocative}

This function happens when a speaker utters taboo words to provoke a certain response from the listener such as violation or anger. The application of taboo words in someone's utterance is believed to be the most effective method for inviting a chaotic reaction. Therefore, some people tend to choose the employment of taboo words in their conversation. Here is the examples:

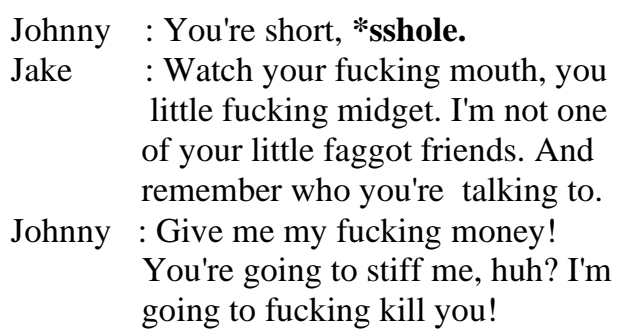
little fucking midget. I'm not one of your little faggot friends. And remember who you're talking to.

Johnny : Give me my fucking money! You're going to stiff me, huh? I'm going to fucking kill you!

In this conversation Johnny utters taboo word to Jake because Jake is fail in his drug transaction and Johnny does not want to hear any reason that Jake try to say. So both of them is started to get angry to each other then followed by Johnny's attacking Jake. In the conversation, Johnny utters taboo word to provoke Jake because he is angry to him.

\section{To mock authority}

This function occurs when people utter taboo words because they are not satisfied with public images such as the government and institutions. Therefore, they utter taboo words that are directed to mock authority in order to show their disbelief about governmental stuffs. This function occurs only 1 time in this movie it happens when Johnny disbelief about how governmental stuffs work.

To make the explanation clearer, there is an example of conversation which shows to mock authority function which is presented below:

Johnny : That will never work.

Lawyer : I'm not saying it will. You're probably looking at some jail time. But if that's our only option, I'll walk you right through custody, we'll do it the right way. I guarantee you do minimum sentence.

Cosmos : Be smart, kid. Let the spooks do the hard time.

Johnny : F*ck that. No jail.

Cosmos : Two years? a piece of cake. Winter-summer, winter- summer, done.

This conversation takes place in Sonny's house, Johnny father. Sonny invites a lawyer to his house to discuss about the kidnapping case which I done by his son. They try to find solution but Johnny does not want to go to jail then he utters taboo word because he is not satisfied with the idea. He utters taboo word because he wants to express his disappointment about reality that is different from what he has expected. $\mathrm{He}$ expects the governmental stuffs don't work that way.

\section{Conclusion and Suggestion Conclusion}

The first objective of this research is to identify and to describe the types of taboo words in Alpha dog movie. All the four types of taboo words that consist of obscenity, profanity, vulgarity, and epithet appear in the movie. The highest frequency of the types of taboo words is obscenity. The lowest frequency is obtained by profanity with. Obscenity becomes the most frequently used taboo words because 
it is considered as the most effective way to draw attention of someone. Moreover, obscenity type is frequently used by the characters when they want to get attention more about what they are speaking. The least frequently used taboo word is profanity. Therefore, it can be noticed that profanity is not effective enough to be used as an attractive word to get people's attention.

The second objective of this research is to describe the functions of taboo words in Alpha dog movie. There are four functions that appear in the series: to show contempt, to draw attention to oneself, to be provocative, and to mock authority. to draw attention to oneself gets the highest percentage. The lowest function is to mock authority with only 1 occurrence. To draw attention to oneself appears as the most frequent function to occur in Alpha dog movie because it can represent the speaker's intention of using taboo words that is to get attention toward other people. In the movie, the characters employ taboo words when they want to get more attention. Then, to mock authority appears as the least function to occur in the movie because of its content of the movie. The story in the Alpha dog movie almost has nothing to do with governmental stuffs until at the end of the story when the discussion is about governmental rule related to crime. Therefore, this kind of theme is not concerned in criticizing governmental stuffs which usually show some negative perspectives about the government in general.

\section{Suggestions.}

1). To Students of Linguistics

In analyzing taboo words, students of Linguistics had better pay more attention to the functions of taboo words which do not always mean that the speaker wants to hurt other people's feeling. They can be functioned to show intimacy or to maintain a good relationship by calling one's name with certain types of taboo words.

2). To English lecturers

A movie which is the representation of human real life can be a good and interesting medium to learn about taboo words. Moreover, using a movie as the medium in learning activity will be much more fun because the students can enjoy the story as well as study the taboo words that are uttered by the characters in the movie.

$3)$. To Other researchers

This research focuses on identifying and describing the types of taboo words, and also describing the functions of taboo words in Alpha dog movie. Similar researches that will be conducted in the future are better to discuss those problems. The other researchers can observe the relationship between the use of taboo words and social status in the society.

\section{References}

Allan, Keith and Burridge, Kate. (2006). Forbidden Words;Taboo and the. Censoring of Language. New York: Cambridge University Press.

Batistella, E.L. (2005). Bad Language: Are Some Words Better Than Others?. New York: Oxford University Press.

Gamble, Teri Kwal \& Michael Gamble. (1984). Communication Works. New York: Random House. Hornby. (2000). Oxford Advanced Learners of Current 
English. New York: Oxford University Press.

Strauss, A. and Corbin, J. (1998). Basic of Qualitative Research: Second Edition: Techniques and Procedures for Developing Grounded Theory. California: SAGE Publication, Inc.

Vanderstoep, Scott W. \& Deirdre D. Johnston. (2009). Research Methods for Everyday Life: Blending Qualitative and Quantitative Approaches. San Francisco: JosseyBass.

Wardhaugh, R. (2006). An Introduction to Sociolinguistics (Fifth Edition). Oxford: Blackwell Publishing Ltd. 